\title{
Analisis Kompetensi Guru Menghadapi Era Revolusi Industri 4.0
}

\author{
Zulkifli \\ STKIP Taman Siswa Bima \\ ijulk.bima@gmail.com
}

\begin{abstract}
Abstrak. The industrial revolution 4.0 is characterized by cyber-physical systems, starting to touched the virtual of the world, in the form of human, machine and data connectivity, all of are which everywhere. This term is known as the Internet of Things (IoT). The 4.0 industrial revolution changed the way of life of various sectors of human life, one of them was education. One of the challenges in the field of education in the era of the industrial revolution 4.0 is the used of internet technology in learning which is part of 21 st century learning. In 21 st century learning, students are required to master their skills, knowledge, and abilities in the field of technology. In order to relized it, a teacher's competency and creativity is needed to face these challenges. Teachers who mastering the knowledge and ability to adapt in new technologies and global challenges can influence the skills and knowledge of students. The inprovement of teacher competency in facing the challenges of learning in the era of the industrial revolution is to attended activity forums such as MGMP, scientific forums, training (training), Higher Order Thinking Skills (HOTS) that can hone the skills of a teacher.
\end{abstract}

Kata Kunci._The Industrial Revolution 4.0, Education, Teacher, Competency.

\section{PENDAHULUAN}

Revolusi industri dimulai dari industri 1.0, 2.0, 3.0, hingga industri 4.0. fase industri merupakan real change dari perubahan yang ada. Industri 1.0 ditandai dengan mekanisme produksi untuk menunjang efektifitas dan efisiensi aktivitas manusia, industri 2.0 dicirikan oleh produksi masal dan standarnisasi mutu, industri 3.0 ditandai dengan penyesuaian masal dan fleksibilitas manufaktur berbasis otomatis dan robot. Industri 4.0 selanjutnya hadir menggantikan industri 3.0 yang ditandai dengan cyber fisik dan kolaborasi manufaktur. Istilah industri 4.0 berasal dari sebuah proyek yang diprakarsai oleh pemerintah jerman untuk mempromosikan komputerisasi manufaktur.

Industri 4.0 menggabungkan teknologi otomatisasi dengan teknologi cyber. Ini merupakan tren otomatisasi dan pertukaran data dalam teknologi manufaktur termasuk sistem cyber fisik, Internet of Things (Iot). Industri 4.0 menghasilkan pabrik cerdas berstruktur moduler, sistem cyber fisik mengawasi proses fisik untuk menciptakan salinan dunia fisik secara virtual dan membuat keputusan yang tidak terpusat.
Lewat IoT sistem cyber fisik berkomunikasi dan bekerja sama satu sama lainnya secara bersamaan. Lewat komputasi awan (cloud computing) layanan internet disediakan dan dimanfaatkan oleh berbagai pihak dalam rantai nilai.

Era revolusi industri 4.0 mengubah cara pandang tentang pendidikan. Perubahan yang dilakukan tidak sekadar cara mengajar, tetapi jauh lebih esensial yakni perubahan cara pandang terhadap konsep pendidikan itu sendiri. Pendidikan setidaknya mampu menyiapkan peserta didiknya menghadapi tiga hal: a) menyiapkan peserta didik untuk bekerja; b) menyiapkan peserta didiknya dapat menyelesaikan masalah; c) menyiapkan peserta didik dapat menggunakan teknologi. Oleh sebab itu, perkembangan di era revolusi industri 4.0 seperti perkembangan sosial, informasi teknologi, dan budaya yang mempengaruhi gaya berpikir peserta didik, maka diperlukan sebuah strategi peningkatan profesinalisme guru untuk menghasilkan guru-guru yang profesional dan dapat menghadapi tantangan global dalam dunia pendidikan ( Lince, 2016)

Proses belajar mengajar guru tidak hanya berperan sebagai penyampai ilmu pengetahuan, akan tetapi juga bertanggung 
jawab terhadap perkembangan kepribadian peserta didik. Menurut Ahmad (2010) mengatakan bahwa guru harus menciptakan proses belajar sedemikian rupa, sehingga dapat merangsang peserta didik untuk belajar efektif dan dinamis dalam memenuhi dan mencapai tujuan yang diharapkan. Dengan dengan kemajuan yang dicapai dalam bidang ilmu pengetahuan dan teknologi akan semakin memicu perubahan yang terjadi diberbagai bidang kehidupan manusia yang sekaligus berdampak pada pergeseran nilai-nilai budaya dan agama dalam kehidupan umat manusia.

Hal inilah yang menjadi tantangan yang harus diantisipasi sedini mungkin agar tantangan yang ada tidak menjadi ancaman melainkan menjadi suatu peluang yang menjanjikan. Guru hendaknya terus membuka wawasan dan kreatif untuk membuat peserta didik bergairah dalam proses belajar dan dapat mengaplikasikan teknologi informasi sehingga menyenangkan serta belajar tidak terbatas ruang dan waktu. Bates (dalam Miarso, 2011) menyatakan bahwa teknologi dapat meningkatkan kualitas dan jangkauan bila digunakan secara bijak untuk pendidikan. Untuk mencapai proses pembelajaran ideal yang menjadi tujuan dan arah dalam pencapaian profesionalisme guru, fasilitas, dan dukungan menjadi perhatian utama pemerintah. Dengan sekian banyak tuntutan dalam mencapai keprofesionalannya, guru harus membuka diri terhadap tantangan globalisasi. Guru harus fleksibel, kerja keras, dan mengembangkan keterampilan teknologi agar pendidikan lebih berkontribusi terhadap produktivitas untuk mencapai daya saing.

Dengan demikian, era revolusi industri 4.0 ini jika guru hanya sebatas mentransfer ilmu pengetahuan kepada peserta didik di kelas, maka peran guru dapat tergantikan oleh teknologi, namun peran guru tidak dapat tergantikan oleh teknologi sacanggih apapun dalam mendidik karakter, moral, dan memberikan keteladanan kepada peserta didik.

Metode yang digunakan adalah studi pustaka dengan teknik deskriptif analisis. Data yang digunakan adalah data kualitatif, karena kajian ini menelaah pustaka dan referensi relevan. Peneliti mengikuti Miles dan Huberman (1994:10) dalam menganalisis data. Cara yang digunakan adalah dengan mereduksi data, menyajikan data, dan men menyajikan data, dan menyimpulakan serta memeriksa hasil penelitian secara berkelanjutan dalam proses penelitian.

\section{HASIL DAN PEMBAHASAN 2.1. Persoalan Pendidikan Kita Data UNESCO dalam Global} Education Monitoring (GEM) Report 2016 menunjukkan bahwa pendidikan di Indonesia menempati peringkat ke-10 dan empat belas negara berkembang. Sedangkan komponen penting dalam pendidikan, yaitu guru menempati urutan ke-14 dari 14 negera berkembang di dunia (Detik.com, 29 April 2019). Masalah pendidikan di Indonesia saat ini diantaranya adalah Mutu dan daya saing pendidikan Indonesia sangat rendah dibandingkan dengan negara-negara lain. Salah satu indikatornya adalah hasil tes Program for International Student Assessment (PISA), yang menempatkan kemampuan anak-anak Indonesia dalam bidang sains, membaca, dan matematika jauh di bawah anak-anak Singapura, Vietnam, Malaysia, dan Thailand (Kompas, 27-28 dan 30 April 2018).

Pangkal persoalannya menurut Agus Suwignyo (Kompas, 2 Mei 2018) yaitu rendahnya kompetensi guru. Meskipun sudah memiliki sertifikat pendidik, namun banyak guru yang kompetensi pedagogik dan profesionalnya tidak memadai. Data dari Kemdigbud.go.id menunjukkan bahwa hasil Uji Kompetensi Guru (UKG) tahun 2015, hasil UKG di bidang pedagogic dan profesional menunjukkan bahwa rata-rata nasional untuk kedua bidang tersebut adalah 53,02. Angka ini masih di bawah standar kompetensi minimal nasional yaitu 55 . Bahkan kompetensi pedagogik yang menjadi kompetensi utama guru, rata-rata nasionalnya hanya mencapai 48,94. Hal ini menunjukkan bahwa kompetensi guru di Indonesia masih rendah.

Hal senada juga diungkapkan oleh Salahuddin Wahid dalam tulisannya yang berjudul "Tak Sembarang Orang Bisa 
Menjadi Guru" dimuat di kompas 16 Maret 2018. Menurutnya masalah utama kita ialah penyediaan pelayanan pendidikan yang bermutu dan tersebar ke semua wilayah. Salahuddin Wahid juga mengutip pendapat Abdul Kadir Baraja yang mendapat gelar doktor honoris causa dari Universitas Negeri Surabaya yang mengatakan bahwa masalah utama pendidikan kita adalah kurangnya jumlah guru yang baik. Hal ini dapat terlihat dari hasil Uji Kompetensi Guru (UKG) dimana kompetensi mereka hanya sedikit di atas skor minimal kelulusan Ujian Kompetensi Guru. Sebagian besar guru (PNS) yang mengikuti UKG, dengan nilai kelulusan 80 , terdapat sekitar 41.000 guru tidak lulus. Akhirnya terpaksa dilakukan UKG ulang dengan nilai batas kelulusan diturunkan menjadi 65 .

\section{Syarifudin Yunus (Detik.com, 1}

Mei 2019) mengatakan bahwa penyebab rendahnya kompetensi guru di Indonesia adalah (1) ketidak sesuaian disiplin ilmu dengan bidang studi yang diampu. Hal ini dikarenakan persebaran guru yang tidak merata di semua wilayah sehingga banyak sekolah yang masih kekurangan guru. Untuk menutup kekurangan guru, pihak sekolah menugaskan guru mengajar beberapa bidang studi agar peserta didik dapat belajar semua bidang studi di sekolah. Ketidak sesuaian disiplin ilmu dengan bidang ajar ini mengakibatkan proses belajar mengajar menjadi tidak maksimal.

Penyebab yang kedua yaitu (2) kualifikasi guru yang belum setara sarjana. Menurut Dirjen PAUD dan DIkmas Kementerian Pendidikan dan Kebudayaan, Harris Iskandar, jumlah guru PAUD di Indonesia mencapai 552.894 orang dan baru $47,79 \%$ yang sudah memenuhi kualifikasi sarjana. (3) Program Peningkatan Keprofesian Berkelanjutan (PKB) guru yang masih rendah. Program ini dirancang untuk meningkatkan kompetensi guru melalui pengembangan diri karena perkembangan ilmu pengetahuan dan teknologi yang sangat cepat. Namun masih banyak guru yang tidak mau mengembangkan diri untuk meningkatkan kompetensinya sesuai dengan perkembangan zaman. Apabila ini terus berlangsung maka guru tidak akan memiliki kompetensi sesuai dengan tuntutan di era Revolusi Industri 4.0. (4) keempat, rekrutmen guru yang belum efektif. Banyak guru yang direkrut tanpa melalui sistem rekrutmen yang benar. Contoh ketika sekolah kekurangan guru, maka sering terjadi penerimaan guru hanya berdasar atas ijazah Sarjana tanpa mempertimbangkan kemampuan calon guru tersebut dalam kegiatan pendidikan dan pembelajaran yang bermutu. Belum lagi proses rekrutmen guru yang memprioritaskan hubungan kekerabatan, bukan seleksi kompetensi. Kondisi ini menjadikan kompetensi guru semakin rendah dan akan menghambat dalam menghadapi Revolusi Industri 4.0

Perkembangan teknologi di era Revolusi Industri 4.0 melahirkan tantangan baru. Tantangan di era ini adalah pengangguran sebagai akibat dari ketidakcukupan pengetahuan dan keterampilan, ketimpangan sosial ekonomi akibat teknologi yang padat modal, serta ancaman terhadap kelestarian lingkungan sebagai akibat eksploitasi sumber daya alam. Arus disrupsi teknologi yang mengabaikan sentralitas pendidikan formal semakin berpotensi mempercepat terempasnya makna penting dunia pendidikan di dalam tatanan baru masyarakat. Sebagai dampaknya, kemiskinan struktural berpotensi menguat dan kesenjangan sosial ekonomi antarwarga akan semakin besar.

\subsection{Pendidikan 4.0}

Pendidikan 4.0 adalah istilah yang dipakai oleh ahli pendidikan untuk mengintegrasikan teknologi cyber dalam pembelajaran. Pendidikan 4.0 merupakan respon terhadap kebutuhan revolusi industry 4.0 dimana mesin dan manusia diselaraskan untuk mendapatkan solusi, memecahkan masalah dan menemukan kemungkinan inovasi baru. Pendidikan pada era industri 4.0 perlu dipandang sebagai pengembangan kompetensi yang terdiri dari tiga komponen besar, yakni kompetensi berpikir, bertindak, dan hidup di dunia (Greenstein, 2012). Komponen berpikir meliputi berpikir kritis, 
berpikir kreatif, dan pemecahan masalah. Komponen bertindak meliputi komunikasi, kolaborasi, literasi digital, dan literasi teknologi. Komponen hidup di dunia meliputi inisiatif, mengarahkan diri (self-direction), pemahaman global, serta tanggung jawab sosial.

Praksis pendidikan di sekolah yang bertumpu pada transfer pengetahuan dari guru ke peserta didik kini tak efektif lagi untuk mempersiapkan peserta didik memasuki ekosistem industry 4.0 yang mengutamakan pengembangan kompetensi Abad ke-21. Pendidikan 4.0 hanya dapat diimplementasikan dengan merujuk pada paradigma baru pendidikan yang bercirikan peserta didik sebagai konektor, creator, dan konstruktivis dalam rangka produksi dan aplikasi pengetahuan serta inovasi (BrownMartin, 2017). Sintesis terhadap pandanganpandangan tentang karakteristik Pendidikan 4.0 mengarah pada ke beberapa fitur pembelajaran berikut:

1. Pembelajaran berpusat pada peserta didik (student centered), memberikan kesempatan bagi peserta didik untuk belajar sebagaimana minat dan kecepatan belajarnya masing-masing;

2. Pembelajaran mengembangkan kemampuan peserta didik menggali sendiri pengetahuan dari sumber-sumber informasi dengan menggunakan internet, sebagai wahana bagi mereka untuk belajar sepanjang hayat (life-long learning);

3. Pemanfaatan infrastruktur ICT dan perangkat pembelajaran virtual untuk memberikan fleksibilitas bagi peserta didik untuk menemukan sumber-sumber belajar yang berkualitas, merekam data, menganalisis data, dan menyusun laporan dan melakukan presentasi;

4. Menekankan belajar hands-on melalui metode pembelajaran yang dinamakan "flipped classroom", yang dengan metode ini peserta didik belajar aspekaspek teoritik pengetahuan di rumah dan melakukan praktik di kelas. Metode ini mengembangkan kebiasaan dan kemampuan belajar mandiri (selflearning) seraya menyediakan waktu belajar lebih longgar bagi pembelajaran di sekolah untuk pengembangan kompetensi;

5. Mengembangkan soft-skills berpikir kritis, kreativitas, dan pembecahan masalah, khususnya pemecahan masalah otentik dan non-rutin;

6. Kolaborasi dan dalam interaksi sosial sebagai pendekatan utama yang digunakan dalam pengembangan kompetensi, untuk memperkenalkan budaya kerja di dunia industry dan dunia kerja di Abad ke-21.

7. Memberikan fleksibilitas untuk proses pembelajaran dalam bentuk blended learning, yang memungkinkan peserta didik berinteraksi, berkolaborasi dan saling belajar satu sama lain dalam setting kelas maupun secara jarak jauh (distance) melalui internet.

\section{Industri 4.0}

\subsection{Guru di Era Revolusi}

Saat ini kita sedang dihadapkan pada era Revolusi Industri 4.0. Era Revolusi Industri 4.0 menekankan pada digital economy, artificial intelligence, big data, dan robotic. Hal tersebut menuntut dunia pendidikan mengonstruksi kreativitas, pemikiran kritis, penguasaan teknologi, dan kemampuan literasi digital (Krjogja.com, 29 April 2019). Sehingga, perubahan dalam dunia pendidikan dan pembelajaran merupakan suatu keniscayaan. Guru dituntut untuk mengubah cara pandang pendidikan baik metode pembelajaran maupun konsep pendidikan sesuai dengan tuntutan era Revolusi Industri 4.0.

Dunia berubah amat cepat. Digitalisasi pendidikan membawa perubahan 
besar. Kini, ruang kelas bukan satu-satunya tempat belajar. Dunia virtual pun bisa menjadi kampus. Terkait dengan itu pula, kini di tengah Revolusi Industri 4.0 sejumlah profesi tergantikan oleh kecerdasan buatan (artificial intelligence). Karena perubahan yang cepat itu, peran guru harus lebih dari mengajar, tetapi juga mengelola belajar siswa. Guru perlu lebih fleksibel, kreatif, menarik, dan lebih menyenangkan bagi siswa.

$$
\text { Unifah Rosyidi dalam }
$$

sambutannya selaku ketua umum PGRI pada upacara hari ulang tahun ke-73 PGRI dan hari guru nasional tahun 2018 mengatakan bahwa di era revolusi industry 4.0 , sistem pendidikan nasional dihadapkan pada tantangan yang amat kompleks tetapi menarik. Dunia hari ini menghadapi fenomena disrupsi seperti lahirnya digitalisasi sistem pendidikan melalui inovasi aplikasi teknologi seperti Massive Open Online Course (MOOC) dan Artificial Intelligence.

$$
\text { MOOC adalah inovasi }
$$

pembelajaran daring yang dirancang terbuka, saling berbagi, terhubung atau berjejaring satu sama lain. Prinsip ini menandai dimulainya demokratisasi pengetahuan yang menciptakan peluang bagi setiap orang untuk memanfaatkan teknologi secara produktif. Sementara Artificial Intelligence adalah mesin kecerdasan buatan yang dirancang untuk melakukan pekerjaan spesifik untuk membantu tugas-tugas keseharian manusia. Di bidang pendidikan artificial intelligence membantu pembelajaran secara infividual, yang mampu melakukanpencarian informasi dan menyajikannya dengan cepat, akurat, dan interaktif. Inilah yang menandai revolusi industri 4.0 khususnya di bidang pendidikan.

Dua hal tersebut mengubah secara fundamental kegiatan belajar mengajar. Ruang kelas mengalami evolusi kearah pola pembelajaran digital yang menciptakan pembelajaran lebih kreatif, partisipatif, beragam, dan menyeluruh. Guru berperan penting dalam mengkontekstualkan informasi dan membimbing peserta didik saat diskusi daring. Para guru perlu mengubah cara mengajar agar lebih menyenangkan dan menarik. Demikian juga peran guru berubah dari sebagai penyampai pengetahuan kepada peserta didik, menjadi fasilitator, motivator, inspirator, mentor, pengembang imajinasi, kreativitas, nilai-nilai karakter, serta team work, dan empati sosial karena jika tidak maka peran guru dapat digantikan oleh teknologi.

Revolusi Industri 4.0 yang sarat akan teknologi yang super cepat akan membawa perubahan yang cukup signifikan, salah satunya terhadap sistem pendidikan di Indonesia. Perubahan dalam sistem pendidikan berdampak pada peran guru sebagai tenaga pendidik. Guru dituntut memiliki kompetensi tinggi untuk menghasilkan peserta didik yang mampu menjawab tantangan Revolusi Industri 4.0. Qusthalani menyebutkan lima kompetensi yang harus dimiliki oleh guru pada era Revolusi Industri 4.0 ini yaitu: 1) educational competence, kompetensi mendidik/pembelajaran berbasis internet of thing sebagai basic skill. 2) competence for technological commercialization, punya kompetensi untuk mendidik siswa memiliki sikap kewirausahaan (entrepreneurship) berbasis teknologi dan hasil karya inovasi siswa. 3) competence in globalization, dunia tanpa sekat, tidak gagap terhadap berbagai budaya, kompetensi hybrid dan keunggulan memecahkan masalah (problem solver competence). 4) competence in future strategies, dunia mudah berubah dan berjalan cepat sehingga punya kompetensi memprediksi dengan tepat apa yang akan terjadi di masa depan berikut strateginya. 5) counselor competence. Mengingat ke depan masalah anak bukan pada kesulitan memahami materi ajar, tetapi lebih terkait masalah psikologis, stress akibat tekanan keadaan yang makin kompleks dan berat, dibutuhkan guru yang mampu berperan sebagai konselor/psikolog (Kemdikbud, 1 Mei 2019). Jadi ketika kita akan memperbaiki mutu pendidikan maka kita harus memperbaiki kualitas guru terlebih dahulu.

Di era disrupsi bukan hanya peserta didik, tetapi guru, dan dosen pun juga harus memiliki keterampilan abad 21. Karena tidak mungkin guru dapat melatih ketrampilan 
tersebut kepada peserta didik jika gurunya sendiri belum menguasainya. Guru harus memiliki kompetensi yang kuat, memiliki softskil yaitu berpikir kritis, kreatif, komunikatif dan kolaboratif. Peran guru sebagai teladan karakter, menebar passion dan inspiratif. Inilah peran yang tak akan dapat digantikan oleh teknologi. Guru harus mampu membangun atmosphere yang dapat memenuhi kebutuhan psikologis peserta didik, yang meliputi: needs for competence, setiap peserta didik butuh merasa bisa, artinya interaksi dalam pembelajaran mampu membuat peserta didik merasa bisa. Hal ini dapat dilakukan dengan jalan memberikan penghargaan atas hasil belajar peserta didik. Needs for Autonomy, setiap peserta didik butuh merasa 'otonom' dengan mendapat kebebasan dan kepercayaan karena setiap pembelajar yang otonom tidak akan bergantung pada guru dalam belajar. Needs for relatedness, setiap peserta didik membutuhkan merasa dirinya bagian dari suatu kelompok, dan berinteraksi dalam kelompok. Jadi proses pembelajaran harus mampu memupuk interaksi kolegialitas dan saling support. Sustainable learning, agar peserta didik mampu melewati era disrupsi, dan memasuki era baru yang disebut Abundant Era, yaitu serba melimpahnya informasi, media dan sumber belajar.

Upaya untuk mencapai kompetensi guru di era Revolusi Industri 4.0 bisa dilakukan dengan 6 cara yaitu (1) sistem rekrutmen guru dilakukan dengan pola yang selektif dan berstandar sesuai kebutuhan perkembangan teknologi. (2) pola peningkatan kompetensi guru yang bersifat bottom up agar setiap permasalahan dan kendala yang dihadapi guru di daerah dapat diakomodir untuk kemudian dikaji bersama. (3) peningkatan profesi guru secara berkelanjutan melalui program PKB. (4) lesson study untuk meningkatkan kompetensi guru. (5) e-literasi. Untuk mencapai ketrampilan abad 21, trend pembelajaran dan best practice juga harus disesuaikan, salah satunya adalah melalui pembelajaran terpadu atau blended learning. Blended learning adalah cara mengintegrasikan penggunaan teknologi dalam pembelajaran yang memungkinkan pembelajaran yang sesuai bagi masing-masing siswa dalam kelas. Blended learning memungkinkan terjadinya refleksi terhadap pembelajaran (wibawa, 2018).

Dengan demikian peran guru tak tergantikan, karena teknologi tidak akan bisa menjadi fasilitator, motivator, inspirator, mentor, pengembang imajinasi, kreativitas, nilai-nilai karakter, serta team work, dan empati sosial. Teknologi juga tidak dapat menggantikan peran guru sebagai pembentuk karakter peserta didik. Namun guru diharapkan untuk terus mengembangkan kompetensinya sehingga masalah terkait dengan mutu pendidikan di Indonesia yang lebih rendah dibandingkan dengan negara lain bisa segera kita selesaikan.

\section{SIMPULAN}

Masalah pendidikan di Indonesia saat ini adalah mutu pendidikan Indonesia sangat rendah dibandingkan dengan negaranegara lain. Hal ini dikarenakan oleh rendahnya kualitas serta kompetensi guru di Indonesia yakni, (1) ketidak sesuain disiplin ilmu dengan bidang studi yang diampu, (2) kualifikasi guru yang tidak setara, (3) Program Peningkatan Keprofesian Berkelanjutan (PKB) guru masih rendah, (4) rekrumen guru yang tidak efektif.

Pendidikan sekolah selalu bertumpu pada transfer pengetahuan dari guru ke peserta didik tidak efektif lagi untuk mempersiapkan peserta didik memasuki ekosistem revolusi industri 4.0 yang selalu mengutamakan pengembangan kompetensi abad ke-21. Pendidikan 4.0 hanya dapat diimplementasikan dengan merujuk pada paradigma baru pendidikan yang bercirikan peserta didik sebagai konektor, kreator, dan konstruktivis dalam rangka produksi dan aplikasi pengetahuan serta inovasi.

Guru di era Revolusi Industri 4.0 perlu memiliki lima kompetensi yang harus dimiliki oleh guru yaitu: 1) educational competence. 2) competence for technological commercialization, 3) competence in globalization, dunia tanpa sekat, tidak gagap terhadap berbagai budaya, kompetensi hybrid 
dan keunggulan memecahkan masalah (problem solver competence). 4) competence in future strategies, dunia mudah berubah dan berjalan cepat sehingga punya kompetensi memprediksi dengan tepat apa yang akan terjadi di masa depan berikut strateginya. 5) counselor competence.

\section{DAFTAR PUSTAKA}

Brown-Martin, G. 2017. Education and the fourth industrial revolution. Report for Groupe Media TFO. https://www.groupemediatfo.org/wpcon tent/uploads/2017/12/FINAL diakses pada 30 April 2020.

Greenstein, L. 2012. Assessing 21 st Century skills: A guide to evaluating mastery and authentic learning. Thousand Oaks, CA: Corwin.

Guru PAUD Harus Lulus Sarjana Pendidikan",

http://www.koranjakarta.com/gurupaudharuslulusan-sarjana-pendidikan/ diakses 2 Mei 2020.

Halili, S. H. (2019). Technological Advancements In Education 4.0, 7(1), 63-69.

Hermann, M., Pentek, T., \& Otto, B. 2016. Design Principles for Industry 4.0 Scenarios. Presented at the 49th Hawaiian International Conference on Systems Science. 6-7 January 2016.

Hinton, K. 2012. A Practical Guide to Strategic Planning in Higher Education. Society for College. University Planning (SCUP).

Hussin, A. A. 2018. Education 4.9 Made Simple: Ideas For Teaching. International Journal of Education \& Literacy Studies, 6(3), 92-98.

Khamova, S. 2013. Weaknesses in the Process of English Language Teaching. International Journal of Humanities and Social Science, 3(20), 33-36.

Mahmudi, Ali. 2009. Mengembangkan Kompetensi Guru Melalui Lesson Study. Jurnal Forum Kependidikan, Volume 28, No. 2, Maret.

Maria, M., Shahbodin, F., \& Pee, N. C. 2016. Malaysian higher education system toward industry 4.0-Current trends overview. Proceeding of the $3 \mathrm{rd}$ International Conference on Applied Science and Technology (AIP Publishing), 1-7.

Miles, M.B., and Huberman, A.M.. 1987. Qualitative Data Analysis: A Sourcebook of New Methods. Newbury Park: Sage Publication.

Nouri J, Karbassi AR, Mirkia S. 2008. Environmental management of coastal regions in the Caspian Sea. Int. J. Environ. Sci. Tech., 5(1): 43-52.

Orr, B. 2013. Conducting a SWOT Analysis for Program Improvement, US-China Education Review A, vol. 3, no. 6, pp. 381-384.

Pardede, P. 2019. Pre-Service EFL Teachers' Perception of Blended Learning. Journal of English Teaching 5(1), pp. 1-14.

Portal Rumah Belajar, Cara Pintar Belajar Tanpa Kertas. http://pena.belajar.kemdikbud.go.id/201 8/12/portal-rumah-belajar-carapintarbelajartanpa-kertas/ diakses $1 \mathrm{Mei}$ 2019.

Razmjoo, S., \& Nouhi, N. 2014. A SWOT Analysis of the Junior High School English program: Grounded Theory Approach. International Journal of Language Learning and Applied Linguistics World, 5(1), 306-312.

Risdianto, Eko. 2019. Analisis Pendidikan Di Era Revolusi Industri 4.0. Bengkulu: Universitas Bengkulu.

Ristekdikti. 2018. Mempersiapkan SDM Indonesia di Era Revolusi Industri 4.0. Kementerian Riset, Teknologi dan Pendidikan Tinggi.

Rohim, Abdur. Bima A, Ridho. Julian, Starlet Gerdi. 2016. Belajar dan Pembelajaran Di Abad 21. Yogyakarta: Universitas Negeri Yogyakarta.

Rosyadi, S. 2014. Revolusi Industri 4.0: Peluang Dan Tantangan Bagi Alumni. Universitas Terbuka.

Rowan, B., Correnti, R., \& Miller, R. J. 2002. What large-scale survey research tells us about teacher effects on student achievement: Insights from the 
Prospects study of elementary schools. Teachers College Record, 104, 15251567.

Sanjaya, W. 2005. Pembelajaran dalam Implementasi Kurikulum Berbasis Kompetensi. Jakarta: Kencana.

Sanjaya, W. 2008. Perencanaan dan Desai Sistem Pembelajaran. Jakarta:Kencana.

Scherer, M. 2003. Keeping good teachers. Alexandria: Association for Supervision and Curriculum Development.

Shute, V.J. \& Emihovich, B. 2018. Assessing Problem-Solving Skills in Game-Based Immersive Environments. In: Voogt J., Knezek G., Christensen R., Lai KW. (eds) Second Handbook of Information Technology in Primary and Secondary Education. Springer International Handbooks of Education. Springer: Cham.

Sukartono. 2017. Revolusi Industri 4.0 dan Dampaknya terhadap Pendidikan di Indonesia. Surakarta: FIP PGSD Universitas Muhammadiyah Surakarta.

Syamsuar\& Reflianto. 2019. Pendidikan dan Tantangan Pembelajaran Berbasis Teknologi Informasi di Era Revolusi Industri 4.0. Malang: Universitas Negeri Malang.

Wagiran. 2010. Implementasi Pendidikan Karakter Dalam Menyiapkan Tenaga Kerja Kejuruan Menghadapi Tantangan Global. Yogyakarta: Fakultas Teknik Universitas Negeri Yogyakarta.

Wahyuni, Dinar. 2018. Peningkatan Kompetensi Guru Menuju Era Revolusi Industri 4.0. Jakarta: Jurnal Info Singkat Vol. X No 24.

Wahyuni, Dinar. 2018. Peningkatan Kompetensi Guru Menuju Era Revolusi Industri 4.0. Jakarta: Info Singkat Vol. X, No 23/II/Puslit.

Wartomo. 2016. Peran Guru Dalam Pembelajaran Era Digital. Prosiding Temu Ilmiah Nasional Guru (Ting) VIII Universitas Terbuka Convention Center. Wibawa, S. 2018. Pendidikan dalam Era Revolusi Industri 4.0. Indonesia "7 Provinsi Raih Nilai Terbaik Uji Kompetensi Guru 2015”,

Jurnal Ilmu Sosial dan Pendidikan https://www.kemdikbud.go.id/ diakses pada 1 Mei 2020.

Yahya, Muhammad. 2018. Era Industri 4.0: Tantangan dan Peluang Perkembangan Pendidikan Kejuruan Indonesia. Orasi Ilmiah Profesor bidang Ilmu Kejuruan Universitas Negeri Makassar.

Zhou, keliang, Zhou, L., \& Liu, T. 2015. Industry 4.0: Towards Future Industrial Opportunities and Challenges. FSKD 2015 : 15-17 August. 